\title{
ANALISIS PERBANDINGAN PERFORMANSI SISTEM RADIO OVER FIBER ANTARA MENGGUNAKAN RADIO TO OPTIC DIRECT CONVERSION DAN IM/DD
}

\author{
Helmi Setiawan ${ }^{1}$, Erna Sri Sugesti ${ }^{2}$, Suwandi $^{3}$ \\ ${ }^{1}$ Program Magister Teknik Telekomunikasi, ${ }^{2}$ Jurusan Teknik Elektro, ${ }^{3}$ Program Perkuliahan Dasar Umum, \\ Sekolah Tinggi Teknologi Telkom, Bandung \\ 1'mte03004@stttelkom.ac.id, ${ }^{2}$ ern@stttelkom.ac.id, ${ }^{3}$ swi@stttelkom.ac.id
}

\begin{abstract}
Abstrak
Jurnal ini mengevaluasi sistem radio over fiber (ROF) menggunakan radio-to-optic direct conversion (ROC) bertingkat, baik ROC/heterodyne detection (HD) maupun ROC/ self heterodyne detection (SHD). Sistem ROF menggunakan intensity modulation/direct detection (IM/DD) bertingkat berdasarkan parameter carrier to noise ratio (CNR). Optimalisasi nilai optical modulation index (OMI) yang dilakukan pada sistem ROF menggunakan ROC bertingkat, karena performansi CNR dari sistem dengan OMI yang identik kurang baik. Dengan menggunakan metoda optimalisasi OMI, CNR sistem ROC/HD dan ROC/SHD lebih besar $18 \mathrm{~dB}$ dan $15 \mathrm{~dB}$ dari sistem IM/DD untuk bandwidth sinyal RF sebesar $150 \mathrm{MHz}$ dan jumlah Radio Base Station (RBS) yang terkoneksi $(N)=20$. Sedangkan untuk bandwidth sebesar 50 MHz dan N = 20, CNR sistem ROC/HD dan ROC/SHD lebih besar $20 \mathrm{~dB}$ dan $17 \mathrm{~dB}$.
\end{abstract}

Kata kunci: radio over fiber, radio-to-optic direct conversion, heterodyne detection, self heterodyne detection

\section{Abstract}

This journal evaluates radio over fiber (ROF) system using cascaded ROC system, either ROC/ heterodyne detection (HD) or ROC/ self heterodyne detection (SHD). This ROF system uses cascaded IM/DD system based on carrier to noise ratio (CNR). The Optimization of an optical modulation index (OMI) done to ROF used cascaded ROC system as CNR performance of a system with identical OMI was not adequate. Using OMI optimization method, the ROC/HD and ROC/SHD schemes provide $18 \mathrm{~dB}$ and $15 \mathrm{~dB}$ CNR improvement over IM/DD scheme when RF signal bandwidth is $150 \mathrm{MHz}$ and the number of RBS $(N)$ is 20. Meanwhile, if RF signal bandwidth is $50 \mathrm{MHz}$ and $N$ is 20 , the ROC/HD and ROC/SHD schemes provide $20 \mathrm{~dB}$ and $17 \mathrm{~dB}$ improvement.

Keywords: radio over fiber, radio-to-optic direct conversion, heterodyne detection, self heterodyne detection.

\section{Pendahuluan}

Sistem ROF menghubungkan antara RBS dan control station (CS) dengan fiber optik. Sistem ROF dengan menggunakan IM/DD bertingkat mempunyai masalah yaitu dispersi dan distorsi intermodulasi akibat hubungan modulator bertingkat. Sistem ROF dengan ROC bertingkat mampu mengatasi kelemahan pada sistem ROF menggunakan IM/DD bertingkat.

Jurnal ini mengevaluasi sistem ROC bertingkat dan IM/DD bertingkat berdasarkan parameter CNR dengan mengasumsikan subcarrier RF tiap RBS yang digunakan hanya satu dan fenomena non-linear diabaikan.

\section{Sistem ROF Menggunakan Skema IM/DD dan ROC Bertingkat}

\subsection{Sistem ROF dengan IM/DD Bertingkat}

Pada ROF konvensional dengan tipe star dan bus, sistem mengalami penurunan performansi akibat banyaknya laser diode (LD) yang dipakai menyebabkan derau dalam sistem.
Untuk menghindari derau tersebut, ini maka digunakan sistem koneksi modulator intensitas bertingkat dengan satu LD. Sistem ROF dengan koneksi bertingkat seperti pada Gambar 1.

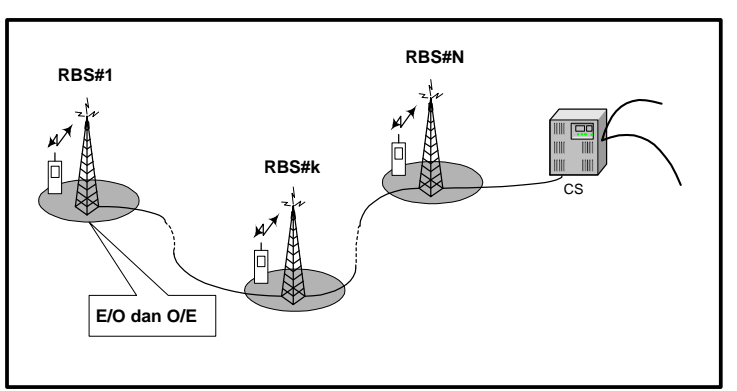

Gambar 1. Sistem ROF bertingkat [9][14][15][4]

Konfigurasi ROF dengan IM/DD bertingkat terdapat pada Gambar 2. Modulator intensitas yang diasumsikan linear ditempatkan antara LD dan photodetector (PD). Setiap modulator memodulasi sinyal subcarrier individu. Keluaran PD merupakan sinyal subcarrier FDM N-tingkat modulator. Ketika sinyal optik dimodulasi dengan modulator yang linier $N$-tingkat, daya optik yang diterima oleh photodiode $\left(P_{I M}\right)$ sesuai Persamaan $(1)-(2)$, yaitu: 


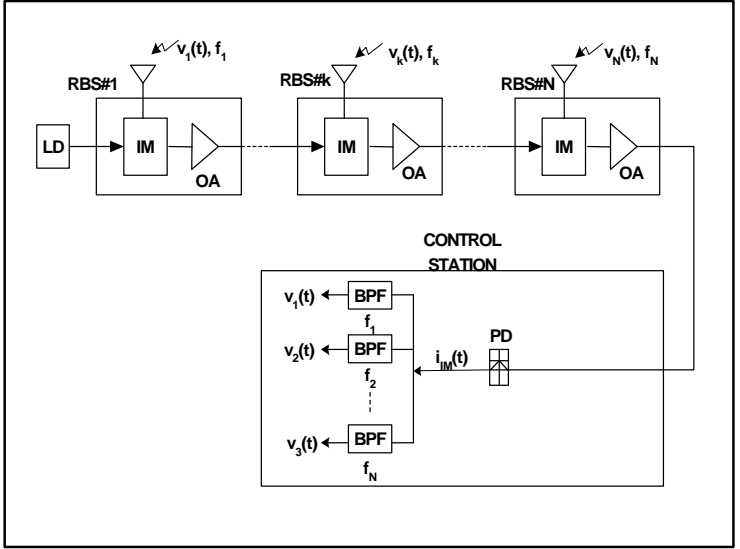

Gambar 2. Sistem ROF dengan IM/DD bertingkat[9]

$$
\begin{aligned}
P_{I M} & =\frac{P_{t}}{L_{f}} \prod_{i=1}^{N}\left(1+O M I \cos \omega_{i} t\right) \\
P_{I M} & =\frac{P_{t}}{L_{f}}\left(1+O M I \sum_{i} \cos \omega_{i} t+\left(O M I^{2} / 2\right) \sum_{i 1 \neq} \sum_{i_{2}} \cos \left(\omega_{i 1} \pm \omega_{i 2}\right) t\right. \\
& \left.+\left(O M I^{3} / 4\right) \sum_{i_{1} \neq} \sum_{i_{2} \neq} \sum_{i_{3}} \cos \left(\omega_{i 1} \pm \omega_{i 2} \pm \omega_{i 3}\right) t+\ldots\right)
\end{aligned}
$$

dengan $P_{t}, \omega_{I}, L_{f}$ adalah daya optik transmitter, frekuensi angular modulasi untuk modulator ke- $i$ dan redaman propagasi antara 2 RBS [9]. Empat komponen pada Persamaan (2) terdiri dari: komponen DC, komponen dasar, distorsi intermodulasi orde 2 (IMD2) dan orde 3 (IMD3). Persamaan tersebut menunjukkan bahwa walaupun secara individu modulator linier, IMD tetap ada, karena hubungan bertingkat antara modulator optik.

Redaman antara penguat yang berdekatan diberikan oleh [9], [14], [15]:

$$
L_{s u b-I M}=L_{f} L_{m}
$$

Bila gain dari setiap penguat optik diasumsikan identik dengan redaman antara dua penguat optik yang berdekatan, maka:

$$
G_{I M}=L_{s u b-I M} \quad \text { (untuk semua penguat) }
$$

Power spectral density dari (ASE) di penerima adalah:

$$
N_{A S E-I M}=\frac{p n_{s p}\left(G_{I M}-1\right) h v}{L_{f}}
$$

dengan $p, G_{I M}$, adalah jumlah penguat optik dan besar penguatan dari setiap penguat optik.

Penghitungan CNR dari setiap sinyal RF dilakukan berdasarkan:

$$
C N R_{I M}=\frac{C}{\sigma_{\text {noise }}^{2}}
$$

di mana $C, \sigma_{\text {noise }}^{2}$ adalah daya total carrier dan daya total derau. Daya carrier didapatkan dari:

$$
C=\frac{1}{2} \Re^{2}\left(P_{t} / L_{f}\right)^{2} O M I^{2}
$$

sedangkan daya total derau pada sistem ini adalah:

$$
\begin{gathered}
\sigma_{\text {noise }}^{2}=\left\{R I N \Re^{2}\left(\frac{P_{t}}{L_{f}}\right)^{2}+2 e \Re\left(\frac{P_{t}}{L_{f}}\right)+2 e \Re N_{A S E-I M} B_{0}+\right. \\
\left.\frac{4 k_{B} T B}{R_{L}}+4 \Re^{2}\left(\frac{P_{t}}{L_{f}}\right) N_{A S E-I M}+4 \Re^{2}\left(\frac{P_{t}}{L_{f}}\right) N_{A S E-I M}^{2} B\right\}_{0}
\end{gathered}
$$

Dalam Persamaan (8) terdapat RIN, derau shot sinyal, derau shot ASE, derau thermal penerima, derau tabrakan antara sinyal dengan ASE, derau tabrakan antara ASE dengan ASE, dan derau intermodulasi. Jumlah IMD3 didapatkan dari [13]:

$$
D_{3}(N, k)=\frac{r}{2}[N-r-1]+\frac{1}{4}\left[(N-3)^{N}-5\right]-\frac{1}{8}\left[1-(-1)^{N}\right](-1)^{N+r}
$$

CNR RBS di tengah jaringan memiliki nilai paling kecil karena IMD3 maksimum di kanal tengah.

\subsection{Sistem ROF Menggunakan ROC Bertingkat}

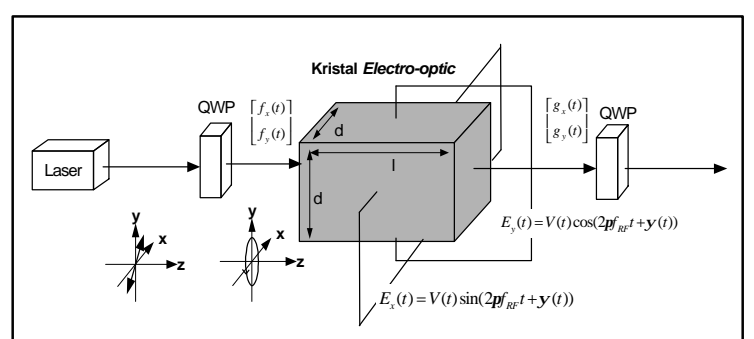

Gambar 3. Konfigurasi dari modulator ROC[9], [14]

Pada Gambar 3, cahaya yang terpolarisasi melingkar ke kanan berpropagasi sepanjang sumbu $\mathrm{z}$ melewati kristal electro-optic $\left(\mathrm{LiNbO}_{3}\right.$ atau $\left.\mathrm{LiTaO}_{3}\right)$ yang di-drive oleh medan elektrik pada sumbu $x$ dan sumbu $y$ yaitu $E_{x}(t)$ dan $E_{y}(t)$. Medan elektrik $E_{x}(t)$ dan $E_{y}(t)$ saling orthogonal, yaitu [9], [14], [15] :

$$
\begin{aligned}
& E_{x}(t)=V(t) \sin \left(2 \pi f_{R F} t+\psi(t)\right) \\
& E_{y}(t)=V(t) \cos \left(2 \pi f_{R F} t+\psi(t)\right)
\end{aligned}
$$

dengan $V(t), f_{R F}$, dan $\Psi(t)$ adalah amplituda, frekuensi dan fasa sinyal RF.

Gelombang cahaya keluaran, $g_{x}(t)$ dan $g_{y}(t)$, sesuai Persaman (12) berikut:

$$
\begin{aligned}
& {\left[\frac{g_{x}(t)}{g_{y}(t)}\right]=\sqrt{P} \cos \left(\pi \frac{V(t)}{V_{\pi}(t)}\right) \cdot e^{j\left[2 \pi f_{0} t-\dot{\phi}_{0}+\dot{\phi}_{s}(t)\right]}\left[\frac{-j}{1}\right]-} \\
& \sqrt{P} \sin \left(\pi \frac{V(t)}{V_{\pi}(t)}\right) \cdot e^{j\left[2 \pi\left(f_{0}+f_{R F}\right) t+\Psi(t)-\phi_{0}+\dot{\phi}_{s}(t)\right]}\left[\frac{+j}{1}\right]
\end{aligned}
$$

dengan $P$ adalah intensitas rata-rata, $V_{\pi}(t)$ tegangan setengah gelombang, $f_{0}$ frekuensi carrier optik, $\phi_{0}$ konstanta fasa, dan $\phi_{s}$ derau fasa sumber optik. Dari Persamaan (12) terlihat bahwa cahaya keluaran modulator terdiri oleh 2 komponen yaitu $f_{0}$ dan frekuensi yang tergeser $f_{0}+f_{R F}$. Jika amplituda $V(t)$ cukup kecil $\left(\pi V(t) / V_{\pi}<<1\right)$, maka $\cos \left(\pi V(t) / V_{\pi}\right) \approx 1$ dan $\sin \left(\pi V(t) / V_{\pi}\right) \approx \pi V(t) / V_{\pi}$. Komponen terakhir di Persamaan (12) adalah replika sinyal input RF dalam band optik, dengan amplituda $V(t)$ dan fasa $\psi(t)$ 
sebagai sinyal input RF. Komponen pertama dapat digunakan sebagai carrier pilot karena amplituda dan fasanya tak termodulasi.

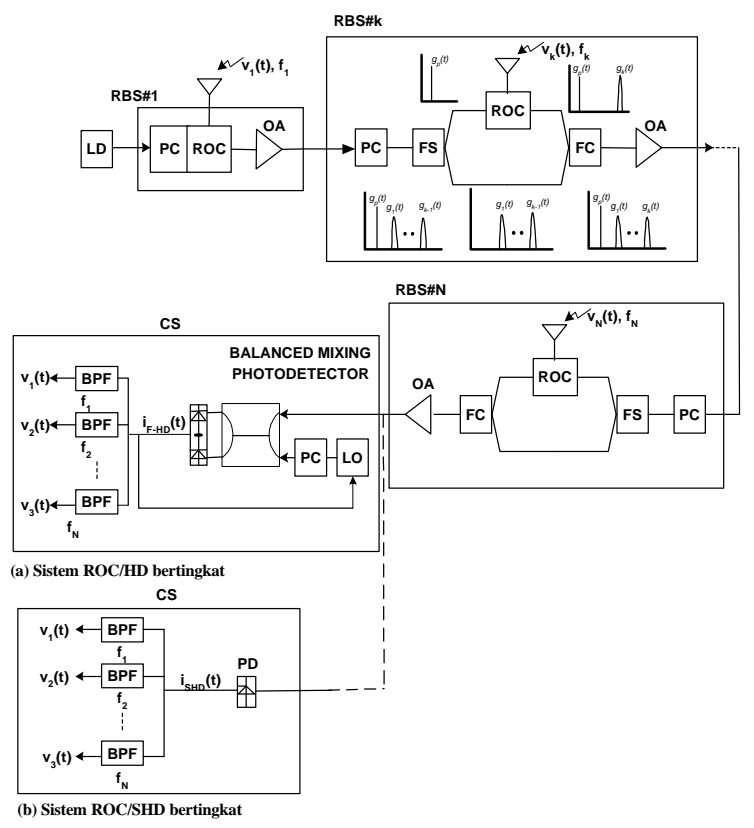

Gambar 4. Sistem ROC bertingkat [9], [14], [15]

Gambar 4(a) dan (b) memperlihatkan skema ROC bertingkat yaitu ROC/HD dan ROC/SHD. Spektrum frekuensi sinyal pada setiap tingkat di RBS juga diperlihatkan pada Gambar 4(b). Pada jaringan ROC, sinyal optik antara carrier pilot $g_{p}(t)$ dan sinyal dari stasiun sebelumnya yaitu: $g_{1}(t), g_{2}(t)$, $\ldots, g_{k-I}(t)$ ditransmisikan ke RBS ke- $k$. Di RBS ke- $k$, setelah melewati polarization controller (PC), carrier pilot dan sinyal dari RBS sebelumnya tersebut dipisahkan oleh frequency splitter (FS). Carrier pilot digunakan untuk memodulasi sinyal RF di RBS ke- $k$ menjadi sinyal optik. Sinyal optik dari RBS ke- $k$ lalu digabungkan dengan komponen sinyal RBS sebelumnya oleh frequency combiner (FC). Mekanisme ini dilakukan untuk menghindari IMD pada jaringan modulator bertingkat. Setelah redaman sisipan modulator dan redaman propagasi antara dua RBS dikompensasi, semua sinyal optik ditransmisikan ke RBS berikutnya.

Di control station (CS), pada sistem ROC/HD di Gambar 4(a), cahaya dideteksi oleh balanced mixing PD setelah menyesuaikan polarisasi sinyal yang diterima dengan sinyal osilator lokal melalui PC. Sinyal RF dihasilkan setelah melewati bandpass filter (BPF). Pada sistem ROC/SHD di Gambar 4(b), cahaya yang diterima dideteksi langsung oleh PD. Pada ROC/SHD tidak adanya LO dan PC membuat struktur penerima menjadi sederhana, tetapi sistem ROC/SHD hanya dapat diterapkan bila terdapat daya yang cukup dari carrier pilot yang diterima di CS.

Analisis performansi sistem ROC dilakukan dengan menggunakan satu subcarrier per RBS. Redaman antara penguat optik dapat diekspresikan:

$$
L_{s u b}=L_{f} L_{s} L_{m} L_{d}
$$

dengan $L_{f}, L_{s}, L_{m}$ dan $L_{d}$ berturut-turut adalah redaman propagasi fiber antara dua RBS berdekatan, redaman sisipan PC, modulator dan FS dengan FC.

Untuk mengkompensasi redaman yang muncul di dalam sistem bertingkat, penguat optik disisipkan di setiap RBS. Gain setiap penguat diatur sama untuk semua redaman antara dia sendiri dengan penguat optik sebelumnya, maka dari itu :

$$
\begin{array}{ll}
G_{1}=L_{s} L_{m} & \text { (penguat di RBS pertama) } \\
G=L_{\text {sub }} & \text { (penguat di RBS lainnya) }
\end{array}
$$

Dalam sistem bertingkat, derau ASE mengumpul dan dikuatkan oleh penguat optik sebanyak jumlah penguat yang terdapat dalam jaringan. Pada masukan di penerima, derau ASE yang terkumpul dapat dianggap sebagai white noise yang ada di seluruh band sinyal subcarrier, sehingga derau ASE mempunyai power density yang sama di setiap band sinyal RF. Dengan asumsi FS dan FC bekerja sempurna sehingga dapat memisahkan dan menggabungkan spektrum frekuensi secara sempurna, maka power spectral density dari ASE yang diterima di penerima [9], [14], [15]:

$$
N_{A S E}=\frac{n_{s p}\left(G_{1}-1\right) h v+(p-1)(G-1) h v}{L_{f}}
$$

dengan $n_{s p}, h, v$ dan $p$ adalah koefisien ASE, konstanta Planck, frekuensi optik dan jumlah penguat optik.

Pada sistem ROC/HD digunakan osilator lokal (LO) dengan persamaan:

$$
g_{L}(t)=\sqrt{2 P_{L}} e^{j\left\{2 \pi f_{L} t+\phi_{L}(t)\right\}}
$$

dengan $P_{L}, f_{L}$ dan $\phi_{L}(t)$ adalah daya LO, frekuensi LO, dan derau fasa LO. Arus IF setelah melalui balanced mixing $P D$ adalah:

$$
i_{I F-H D}(t)=i_{C-H D}(t)+\sum_{k=1}^{N} i_{k-H D}(t)+n_{H D}(t)
$$

dengan $i_{C-H D}(t), i_{k-H D}(t), N$ dan $n_{H D}(t)$ merupakan arus carrier, sinyal dari RBS ke- k, jumlah RBS yang terkoneksi ke sistem, dan derau dalam sistem ROC/HD. Photocurrent dari carrier dan sinyal dari RBS ke-k diekspresikan [9], [14], [15]:

$$
\begin{aligned}
& i_{C-H D}=2 \Re \sqrt{P_{C} P_{L}} \cdot \cos \left[2 \pi f_{I F} t+\Delta \phi(t)\right] \\
& i_{k-H D}=2 \Re \sqrt{P_{r, k} P_{L}} \cos \left[2 \pi\left(f_{I F}+f_{R F}+k \Delta f\right) t+\Delta \phi(t)+\theta_{k}(t)+\frac{\pi}{2}\right]
\end{aligned}
$$

di mana $e, \alpha, P_{C}, P_{r}, k, f_{I F}, f_{R F}, \Delta f, \Delta \phi(t)$, dan $\theta(t)$ berturut-turut adalah muatan elektron, konstanta electro-optic, daya yang diterima dari carrier pilot, daya sinyal optik yang diterima dari RBS ke- $k$, frekuensi sinyal IF $\left(f_{I F}=f_{O}-f_{L}\right)$, frekuensi radio subcarrier, interval frekuensi antara dua sinyal RF yang berdekatan, derau fasa dari sinyal optik $\left(\Delta \phi(t)=\phi_{O}(t)-\phi_{L}(t)\right)$ dan fasa sinyal RF ke- $k$.

Daya terima dari carrier pilot $\left(P_{C}\right)$ dan daya optik diterima dari RBS ke- $k\left(P_{r, k}\right)$ adalah: 


$$
\begin{aligned}
& P_{C}=\frac{P_{t}}{L_{f^{\prime}}} \cdot\left[\prod_{k=1}^{N} \cos \left(\pi O M I_{k}\right)\right]^{2} \\
& P_{r, k}=\frac{P_{t} \cdot L_{m}^{(N-k)}}{L_{f^{\prime}}}\left[\sin \left(\pi O M I_{k}\right) \cdot\left\{\prod_{j=1}^{k-1} \cos \left(\pi O M I_{j}\right)\right\}\right]^{2}
\end{aligned}
$$

dengan $P_{t}=$ daya optik dari transmitter dan $O M I_{k}$ adalah OMI dari RBS ke- $k$ yang didefinisikan:

$$
O M I_{k}=\frac{A_{k}}{V_{\pi}}
$$

dengan $A_{k}=$ amplituda dari sinyal RF ke- $k$. Daya sinyal optik yang diterima dari RBS ke- $k$ adalah:

$$
P_{H D, k}=2 \Re^{2} P_{r, k} P_{L}
$$

Daya total derau dalam sistem ROC/HD diberikan oleh persamaan (25) di bawah ini, di mana $\operatorname{Pr}, B_{0}$, $k_{B}, T, R_{L}$ dan $B$ berturut-turut adalah daya optik total yang diterima, bandwidth filter optik, konstanta Boltzman, suhu derau, hambatan beban, dan bandwidth sinyal RF.

$$
\begin{aligned}
\sigma_{N D, \text { total }}^{2} & =\left\{R I N \quad e^{2} \alpha^{2} P_{T} P_{L}+2 e^{2} \alpha P_{r}+2 e^{2} \alpha P_{L}\right. \\
& +2 e^{2} \alpha P_{L}+2 e^{2} \alpha N_{A S E} B_{0}+\frac{8 k_{B} T}{R_{L}}+4 e^{2} \alpha^{2} P_{L} N_{A S E} \\
& \left.+4 e^{2} \alpha^{2} P_{r} N_{A S E}+4 e^{2} \alpha^{2} N_{A S E}^{2} B_{0}\right\}_{B}
\end{aligned}
$$

Daya optik total yang diterima dapat dinyatakan:

$$
P_{r}=P_{c}+\sum_{k=1}^{N} P_{r, k}
$$

CNR sinyal RF dari RBS ke-k yaitu:

$$
C N R_{H D, k}=\frac{P_{H D, k}}{\sigma_{H D, \text { total }}^{2}}
$$

Pada sistem ROC/SHD, arus keluaran PD adalah:

$$
i_{S H D}(t)=\sum_{k=1}^{N} i_{k-H D}(t)+n_{S H D}(t)
$$

dengan $i_{k-S H D(t)}$ dan $n_{S H D(t)}$ adalah arus sinyal RBS ke- $k$ dan derau. Sinyal dari RBS ke- $k$ adalah:

$$
i_{k-S H D}=2 \Re \sqrt{P_{r, k} P_{L}} \cdot \cos \left[2 \pi\left(f_{R F}+k \Delta f\right) t+\theta_{k}(t)\right]
$$

Daya sinyal dari RBS ke-k diberikan oleh:

$$
P_{H D, k}=2 e^{2} \alpha^{2} P_{r, k} P_{C}
$$

dengan $P_{r, k}$ diberikan oleh Persamaan (13). Derau total dalam sistem dinyatakan Persamaan (31):

$$
\begin{gathered}
\sigma_{S H D, \text { total }(O A)}^{2}=\left\{R I N e^{2} \alpha^{2} P_{r}^{2}+2 e^{2} \alpha P_{r}+\right. \\
2 e^{2} \alpha N_{A S E} B_{0}+\frac{4 k_{B} T}{R_{L}}+4 e^{2} \alpha^{2} P_{r} N_{A S E} \\
\left.+4 e^{2} \alpha^{2} N_{A S E}^{2} B\right\} B_{0}
\end{gathered}
$$

Oleh karena itu, CNR dari RBS ke- $k$ adalah:

$$
C N R_{S H D, k}=\frac{P_{S H D, k}}{\sigma_{S H D, t o t a l}^{2}}
$$

Ketika jumlah subcarrier lebih dari satu, penurunan CNR akibat IMD yang akibat dari ketidaklinearan modulator akan muncul. Namun demikian, tujuan sistem bertingkat masih dapat dicapai, yaitu berkurangnya penurunan CNR oleh distorsi intermodulasi pada modulator bertingkat.

\section{Analisis Performansi CNR Sistem ROC Bertingkat dan Optimalisasi}

Tabel 1 menunjukkan berbagai parameter yang digunakan dalam analisis performansi CNR sistem.

Tabel 1. Parameter untuk analisis

\begin{tabular}{|l|l|}
\hline Daya laser lokal & $10 \mathrm{dBm}$ \\
\hline Relative Intensity Noise $:$ RIN & $-152 \mathrm{~dB} / \mathrm{Hz}$ \\
\hline Responsivitas : $\Re$ & $0.8 \mathrm{~A} / \mathrm{W}$ \\
\hline Hambatan Beban $: R_{L}$ & $50 \Omega$ \\
\hline Suhu derau & $300 \Omega$ \\
\hline Bandwidth ASE & $1 \mathrm{THz}$ \\
\hline Redaman sisipan PC $: L_{s}$ & $3 \mathrm{~dB}$ \\
\hline Redaman sisipan modulator: $L_{m}$ & $3 \mathrm{~dB}$ \\
\hline Redaman sisipan FS+FC $: L_{d}$ & $4 \mathrm{~dB}$ \\
\hline Jarak antar RBS & $100 \mathrm{~m}$ \\
\hline Redaman fiber optik & $0,2 \mathrm{~dB} / \mathrm{km}$ \\
\hline
\end{tabular}

\subsection{Penggunaan OMI identik di setiap RBS}

Gambar 5 memperlihatkan hubungan antara CNR dan orde RBS $(k)$ dalam kasus penggunaan OMI identik dan penguat optik untuk setiap RBS. Jumlah RBS yang terkoneksi dalam sistem $(N)$ sebanyak 10 buah. Dalam sistem ROC, baik ROC/HD maupun ROC/SHD, saat semua OMI diatur sama untuk semua RBS, CNR sinyal dari RBS yang terdekat CS memiliki nilai terkecil. Hal ini disebabkan daya carrier optik yang tersisa untuk RBS ini memiliki daya terendah, karena digunakan untuk modulasi di RBS yang sebelumnya.

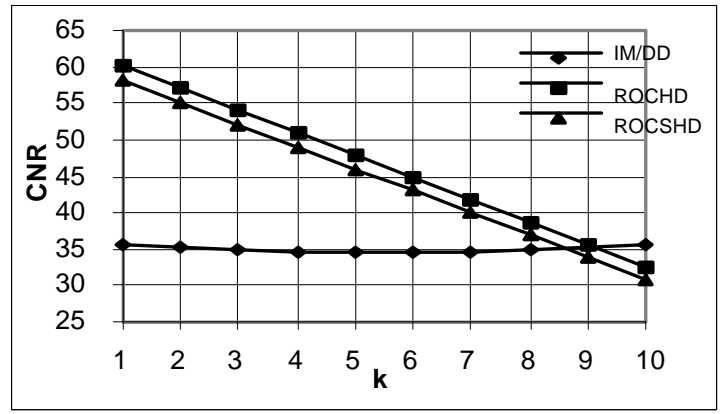

Gambar 5. Perbandingan CNR untuk setiap orde RBS dengan $\mathrm{N}=10$

Sebaliknya dengan sistem IM/DD bertingkat, CNR sinyal dari RBS di tengah saluran memiliki nilai terkecil, karena pada hubungan bertingkat membangkitkan distorsi intermodulasi yang maksimum pada band tengah frekuensi subcarrier.

Penentuan nilai OMI identik untuk sistem ROC/HD dan ROC/SHD dilakukan dengan mencari nilai OMI identik yang dapat memaksimalkan CNR 
dari RBS yang terdekat dengan CS. Sedangkan untuk sistem IM/DD dilakukan dengan mencari nilai OMI yang dapat memaksimalkan CNR di tengah jaringan. Gambar 6 merupakan grafik hubungan antara OMI identik yang menghasilkan CNR maksimum dan jumlah RBS yang terkoneksi.

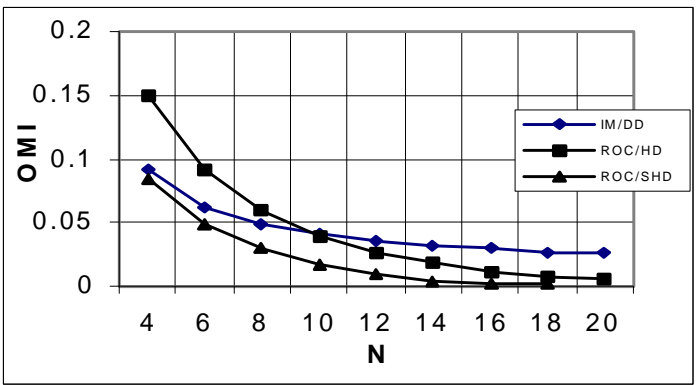

Gambar 6. Perbandingan OMI identik yang menghasilkan CNR maksimum

Gambar 7 menunjukkan hubungan CNR terhadap jumlah RBS terkoneksi dengan penggunaan OMI identik di setiap RBS untuk semua sistem.

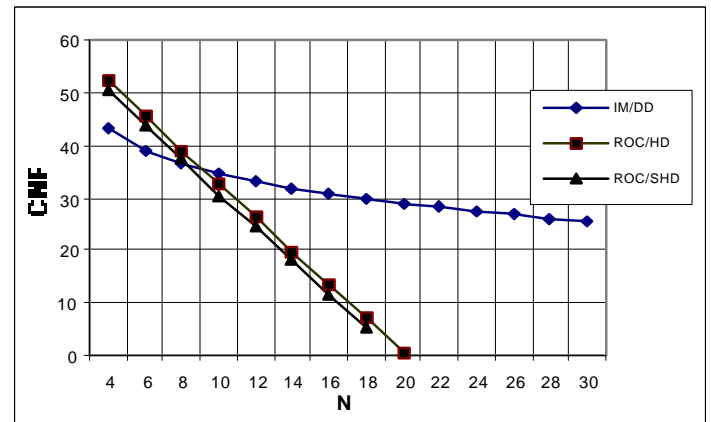

Gambar 7. Perbandingan CNR untuk semua sistem dengan penggunaan OMI identik.

Terlihat pada sistem ROC/HD maupun ROC/SHD CNR mempunyai nilai yang lebih buruk daripada IM/DD. Hal ini disebabkan penggunaan OMI yang identik membuat carrier optik yang tersisa untuk RBS terdekat dengan CS kecil, sehingga CNR pada RBS ini kecil. Dengan semakin bertambahnya $N$, CNR akan semakin kecil pula bahkan mencapai nol pada $N=20$.

\subsection{Optimalisasi OMI}

Optimalisasi OMI dapat mengatasi performansi CNR yang buruk pada sistem ROC dengan OMI identik $^{[1][4]}$. Optimalisasi OMI dilakukan dengan cara mengatur OMI di setiap RBS. Untuk lokasi RBS yang lebih jauh dari CS diberikan nilai OMI lebih kecil dari yang lebih dekat dari CS. Akibatnya nilai CNR turun pada RBS yang lebih jauh dari CS dan CNR naik pada RBS yang lebih dekat CS. CNR dari setiap RBS dalam sistem akan bernilai sama. Kondisi nilai OMI masing-masing RBS dapat diturunkan sebagai berikut [9], [14] :

$$
C N R_{k}=C_{N} R_{k+1} \quad(k=1,2, \ldots \ldots, N-1)
$$

OMI untuk sistem ROC/HD dan ROC/SHD dapat diekspresikan sebagai [9]:

$$
\left(\sin \left(\pi O M I_{k}\right)\right)^{2}=L_{m}\left(\sin \left(\pi O M I_{k+1}\right)\right)^{2}\left(\cos \left(\pi O M I_{k}\right)\right)^{2}
$$

Dengan mengubah persamaan (24) diperoleh hasil:

$$
O M I_{k}=\frac{1}{\pi} \arctan \left(\sqrt{L_{m}} \cdot \sin \left(\pi O M I_{k+1}\right)\right)
$$

Dengan lebih dulu menentukan OMI pada RBS ke- $N$ sebagai RBS yang terdekat dengan CS, melalui Persamaan (35) ditentukan secara terurut OMI pada RBS ke- $(N-1),(N-2), \ldots, 1$. Dalam sistem ROC/HD, pada RBS ke- $N$ ditentukan $\mathrm{OMI}_{N}=0,5$ untuk menggunakan semua carrier pilot optik agar dicapai CNR maksimum. Pada sistem ROC/SHD, agar CNR maksimal, pada RBS ke- $N$ ditentukan nilai khusus $\mathrm{OMI}_{N}=0,11$ agar tetap tersedia daya yang cukup dalam carrier pilot optik untuk deteksi selfheterodyne, karena signal-ASE beat noise dominan .

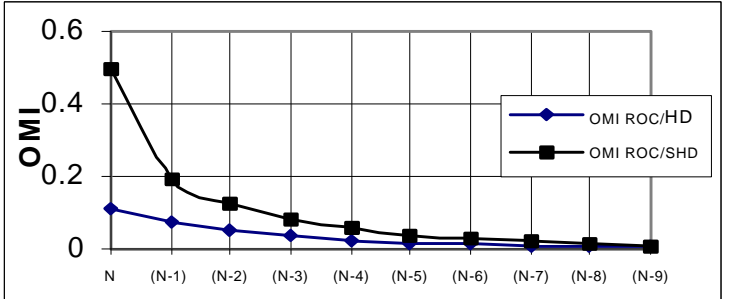

Gambar 8. OMI optimum untuk sistem ROC/HD dan ROC/SHD

Gambar 8 menunjukkan hubungan antara OMI optimum dan orde RBS. Semakin jauh RBS ditempatkan dari CS, semakin kecil pula OMI, sehingga daya carrier optik tersisa masih cukup untuk RBS yang lebih dekat ke CS. Dari Persamaan (15) dapat diketahui bahwa bila terdapat RBS baru ditambahkan ke RBS yang terjauh dari CS, hanya diperlukan penentuan OMI optimum untuk RBS baru, tanpa ada perubahan pada OMI yang lain.

\subsection{Evaluasi Peningkatan Performansi CNR}

Gambar 9 menunjukkan hubungan antara CNR untuk semua sistem baik itu sistem ROC maupun IM/DD dan jumlah RBS yang terkoneksi dalam kasus penggunaan penguat optik untuk setiap RBS.

Dengan menggunakan OMI optimum, pada RBS yang terdekat CS terjadi peningkatan CNR daripada penggunaan OMI identik pada setiap RBS. Sistem ROC dengan OMI optimum memperoleh peningkatan CNR melebihi sistem IM/DD. Distorsi intermodulasi akibat hubungan bertingkat akan muncul pada sistem IM/DD ketika lebih dari dua RBS terkoneksi, sehingga menurunkan CNR.

Pada Gambar 9 terlihat bahwa pada bandwidth sinyal radio $B=150 \mathrm{MHz}$ dan $N=20$, CNR untuk sistem ROC/HD dan ROC/SHD lebih besar $18 \mathrm{~dB}$ dan $15 \mathrm{~dB}$ dari sistem IM/DD. CNR pada sistem ROC/SHD lebih kecil 2,5 dB dari sistem ROC/HD dengan OMI optimum. Penggunaan carrier optik 
yang berfungsi sebagai osilator lokal pada sistem ROC/SHD menyebabkan penurunan CNR.

Untuk $B=50 \mathrm{MHz}$ dan $N=20$ diperlihatkan di Gambar 10, CNR untuk sistem ROC/HD dan ROC/SHD lebih besar $20 \mathrm{~dB}$ dan $17 \mathrm{~dB}$ dari sistem IM/DD. Peningkatan CNR dengan $B=50 \mathrm{MHz}$ lebih baik daripada sistem dengan $B=150 \mathrm{MHz}$. Hal ini terjadi karena berkurangnya daya derau akibat semakin sempitnya banwidth $B$. Peningkatan CNR pada sistem ROC lebih besar daripada sistem IM/DD karena adanya distorsi intermodulasi.

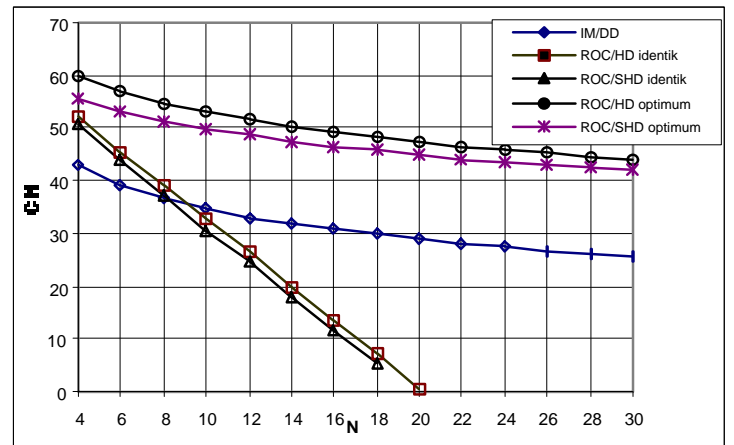

Gambar 9. Perbandingan CNR dengan $\mathrm{B}=150 \mathrm{MHz}$

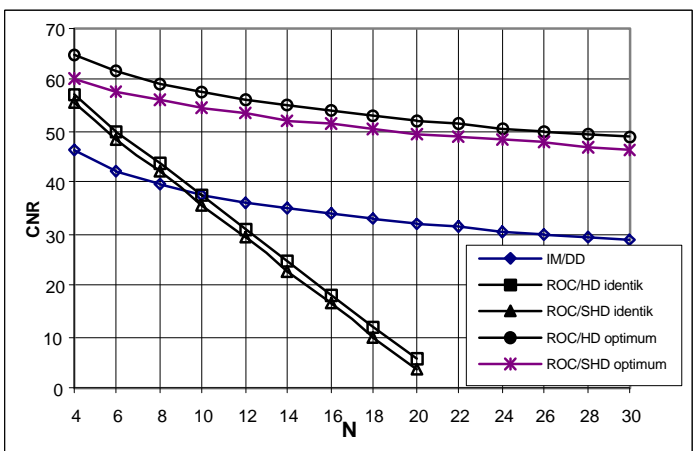

Gambar 10. Perbandingan CNR dengan $\mathrm{B}=50 \mathrm{MHz}$

Untuk penambahan RBS baru di lokasi RBS yang terjauh dari $\mathrm{CS}$, nilai OMI optimumnya diperoleh dari metode optimalisasi OMI. Perubahan OMI pada RBS lain tidak diperlukan. Bila terdapat penambahan RBS baru antara 2 RBS dalam sistem, penentuan OMI untuk RBS baru dapat dilakukan dengan dua cara, yaitu menggunakan OMI suboptimum dan melakukan reoptimalisasi. OMI suboptimum adalah nilai OMI rata-rata dari OMI yang berdekatan dengan RBS baru tersebut.

Gambar 11 memperlihatkan penurunan CNR akibat penambahan RBS baru di antara RBS dalam sistem ROC/HD dengan $\mathrm{N}=10$. CNR di setiap RBS dibandingkan antara penggunaan OMI sub-optimum dan reoptimalisasi. Pada OMI sub-optimum, CNR pada RBS dengan orde lebih kecil dari RBS baru akan mengalami kenaikan, sedangkan orde lebih tinggi mengalami penurunan CNR bila dibandingkan dengan reoptimalisasi. Semakin dekat letak RBS baru pada CS, penurunan CNR menjadi semakin tajam. Tanpa reoptimalisasi OMI, hanya sedikit RBS yang dapat ditambahkan ke RBS yang berlokasi di dekat CS. Pada sistem ROC/SHD, penurunan CNR muncul dalam pola yang sama seperti pada sistem ROC/HD. Terdapat dua cara untuk mengkompensasi penurunan ini, yaitu dengan mempersiapkan margin daya untuk antisipasi penurunan dan reoptimalisasi.
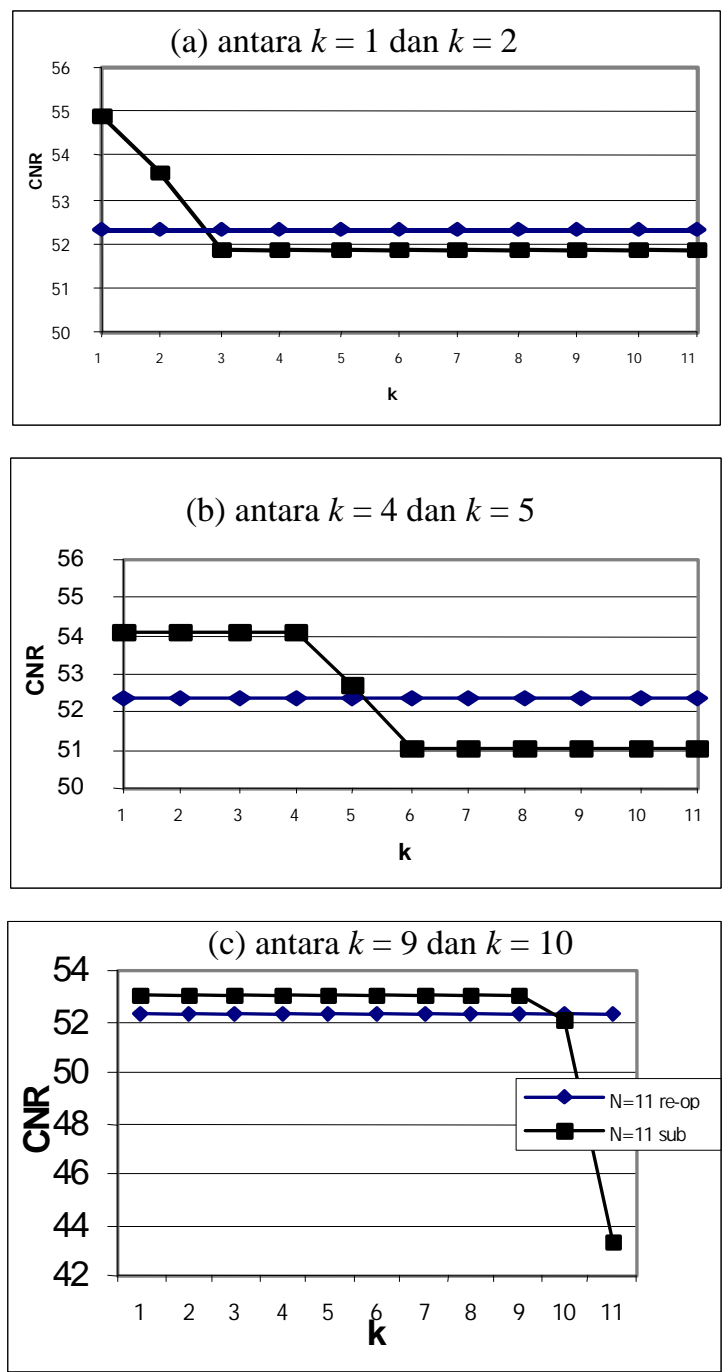

Gambar 11. Perbandingan CNR pada sistem 10 RBS antara penggunaan OMI sub-optimum terhadap reoptimalsasi dalam kasus penambahan 1 RBS baru

Gambar 12 menunjukkan hubungan antara jumlah maksimum RBS terkoneksi dan redaman sisipan modulator optik. Karena sistem IM/DD hanya mempunyai redaman sisipan modulator, maka perbandingan sistem ROC dengan sistem IM/DD dapat dilakukan dari redaman modulator pada sumbu horisontal. Dalam perhitungan, diasumsikan kebutuhan CNR sebesar $32 \mathrm{~dB}$ termasuk dengan margin $20 \mathrm{~dB}$ untuk mencapai probabilitas error $10^{-6}$ pada sinyal QPSK $^{[1][4]}$. Sistem ROC/HD dan ROC/SHD skema OMI optimum dapat menampung lebih banyak RBS daripada sistem IM/DD meskipun dalam redaman sisipan modulator yang relatif tinggi. Sistem ROC/SHD dapat menampung paling sedikit 2 kali jumlah RBS dari sistem IM/DD dalam hal redaman total dari $\mathrm{PC}, \mathrm{FS}, \mathrm{FC}=15 \mathrm{~dB}$. 


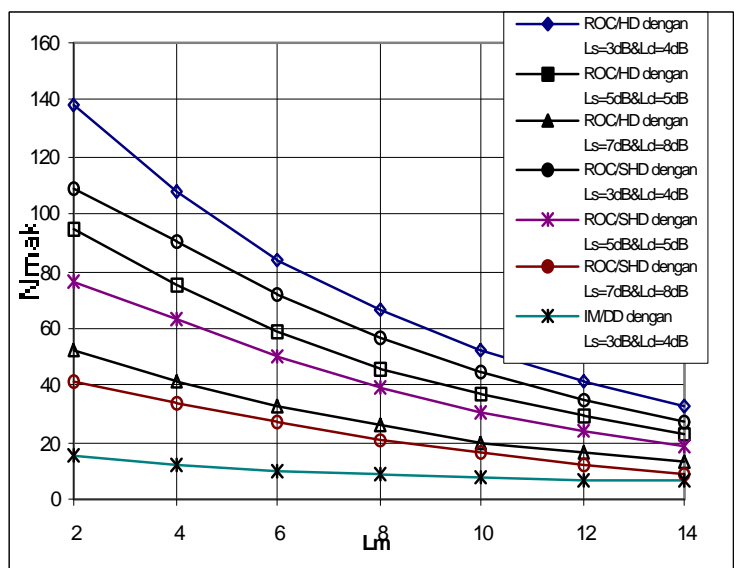

Gambar 12. Pengaruh besarnya redaman sisipan terhadap jumlah maksimum RBS yang terkoneksi

\section{Kesimpulan}

Berdasarkan analisis performansi CNR sistem ROF menggunakan ROC bertingkat dan IM/DD bertingkat, disimpulkan bahwa CNR sistem ROC/HD dan ROC/SHD dengan OMI identik lebih rendah dari sistem IM/DD. Nilai CNR sistem ROC/HD dan ROC/SHD dengan OMI optimum lebih besar $18 \mathrm{~dB}$ dan $15 \mathrm{~dB}$ daripada sistem IM/DD untuk bandwidth sinyal RF $150 \mathrm{MHz}$ dan $\mathrm{N}=20$, dan lebih besar $20 \mathrm{~dB}$ dan $17 \mathrm{~dB}$ daripada sistem IM/DD untuk bandwidth sinyal RF sebesar $50 \mathrm{MHz}$ dan $\mathrm{N}=20$. Dengan OMI optimum, makin sempit bandwidth sinyal RF, peningkatan CNR sistem ROC semakin besar daripada dengan sistem IM/DD.

Pada penambahan RBS baru setelah RBS yang terjauh dengan CS, OMI optimum dapat ditentukan langsung dengan metode optimalisasi OMI, tanpa reoptimalisasi pada RBS lain. Pada penambahan beberapa RBS baru di antara 2 RBS dalam sistem ROC yang letaknya di dekat CS, diperlukan proses reoptimalisasi. Dengan OMI optimum, sistem ROC/HD dan ROC/SHD dapat mengakomodasi lebih banyak RBS daripada sistem IM/DD, walaupun terjadi redaman sisipan modulator yang tinggi dengan kebutuhan CNR $32 \mathrm{~dB}$, termasuk margin daya $20 \mathrm{~dB}$, untuk memenuhi probabilitas error $10^{-6}$

Perlu perencanaan lebih kompleks pada realisasi sistem ROC daripada sistem IM/DD.

\section{Daftar Pustaka}

[1] Cox, C., Ackerman E., Helkey R., Betts G. E., Techniques and Performance of IntensityModulation Direct-Detection Analog Optical Links. IEEE Trans. on Microwave Theory and Tech. Vol 45 No 8. Agustus 1997.

[2] Domon, W., Shibutani M., Emura K., SCM Optical Multiple-Acces Network with Cascade Optical Modulator. IEEE Phot. Tech. Letter Vol. 5 No. 9. September 1993.
[3] Hofstetter, R., Schmuck H., Heidenmann R., Dispertion Effects in Optical Milimeter-Wave System Using Self-Heterodyne Method for Transport and Generatio. IEEE Trans. on Microwave Theory and Tech. Vol 43 No 9. September 1995.

[4] Ishii, Y., Tsukamoto K., Morinaga N., Coherent Fiber-Optic Microcellular Radio Communication System Using RF-to-Optic Conversion Scheme. IEEE Trans. Microwave Theory \& Tech., vol.43 no.9. pp.2241-2248. September 1995.

[5] Junedi. 2001. Analisa Perbandingan Performansi Sensitivitas Fotodetektor Dengan dan Tanpa EDFA. Tugas Akhir STTTelkom. Bandung.

[6] Killen, H. B. 1991. Fiber Optic Communication. Prentice Hall. New Jersey.

[7] Komaki, S., Tsukamoto K., Okada M., Multiband operation of Multimedia Mobile Radio on the Virtual Radio Free Space Networ. Proc. $2^{\text {nd }}$ Intl Workshop on MoMuS2. vol. 1 no.1. pp.1-4. April 1995.

[8] Park, J., Elrefaie A. F., Lau K. Y., Fiber Chromatic Dispersion Effect on Multichannel Digital Milimeter Wave Transmission, IEEE Phot. Tech. Lett. Vol. 8 No. 12. Des. 1996.

[9] Suwonpanich, P., Tsukamoto K., Komaki S., Proposal of Radio-over-Fiber Using Cascaded Radio-to-Optic Direct Conversion Scheme, IEICE Trans Comm. vol. E83-B No. 8 Agustus 2000.

[10] Sabella R., Performance Analysis of Wireless Broadband System Employing Optical Fiber Link. IEEE Trans. On Comm. Vol 47 No.5. Mei 1999.

[11] Saleh, B. E. A., Teich M. C., Fundamental of Photonic. 1991. John Wiley \& Sons. Inc.

[12] Senior, J. M. 1992. Optical Fiber Communication. Prentice Hall.

[13] Sugesti, E. S. Investation of IMD based on 16QAM SCM for Microcellular Radio Over Fiber Application. Thesis for the degree of MSc. Manchester Metropolitan University. Oktober 1998.

[14] Suwonpanich, P., Shoji Y., Tsukamoto K., Komaki S. Proposal of Cascaded Radio-Optic Direct Conversion Radio Highway. Proc. 1997 Asia Pasific Microwave Conf (APMC'97), vol.1 pp.385-388. Hong Kong. Des. 1997.

[15] Suwonpanich, P., Shoji Y., Tsukamoto K., Komaki S. Study on Cascaded Radio-Optic Direct Conversion Radio Highway Using Optical Amplifier. (APMC'98). Vol. 1 pp. 317320. Yokohama. Jepang. Desember 1998.

[16] Wu, J., Wu J.S, Tsao H. W., A Fiber distribution System for Microcellular Radio. IEEE Phot. Tech. Letter. Vol. 6 No. 9. September 1994. 